\title{
Reduction of Plasma NEFA Concentration by Nicotinic Acid Enhances the Response to Insulin in Feed-Restricted Holstein Cows
}

\author{
J. A. A. Pires, J. B. Pescara, and R. R. Grummer ${ }^{1}$ \\ Department of Dairy Science University of Wisconsin, Madison 53706
}

\section{ABSTRACT}

The objective was to investigate the relationship between elevated plasma nonesterified fatty acid (NEFA) concentration and insulin resistance in Holstein cows. Six nonlactating, nongestating, ruminally cannulated Holstein cows were blocked by body condition score and randomly assigned to a sequence of 2 treatments in a crossover design. Cows were offered legume and grass hay ad libitum supplemented with minerals and vitamins and were allowed free access to water and a trace mineralized salt block. Mobilization of body reserves was stimulated by withdrawing forage for $48 \mathrm{~h}$ before initiation of treatments. Treatments consisted of 11 hourly abomasal infusions of water (control) or nicotinic acid (NA; $6 \mathrm{mg} / \mathrm{h}$ per $\mathrm{kg}$ of body weight) as an antilipolytic agent. Infusions of NA decreased plasma NEFA concentration from $545 \mu \mathrm{Eq} / \mathrm{L}$ to approximately 100 $\mu \mathrm{Eq} / \mathrm{L}$ within $2 \mathrm{~h}$ after initiation of treatments, and differences were maintained throughout infusions. Intravenous glucose tolerance test was performed $8 \mathrm{~h}$ after initiation of treatments and was followed by 3 $\mathrm{h}$ of blood sampling. The reduction of plasma NEFA concentration led to significantly greater glucose clearance rate $(1.9$ vs. $1.2 \% / \mathrm{min})$ and to decreased glucose half-life ( 37 vs. $58 \mathrm{~min}$ ), time to reach basal concentration (81 vs. $114 \mathrm{~min}$ ) and glucose response area under the curve during $180 \mathrm{~min}$ of sampling [6,942 vs. 10,085 $(\mu \mathrm{IU} / \mathrm{mL}) \times 180 \mathrm{~min}]$. Enhanced glucose clearance was achieved when plasma NEFA was reduced by NA, despite lower insulin concentration (70.0 vs. $97.9 \pm 13.4$ $\mu \mathrm{IU} / \mathrm{mL}$ ) and a tendency for smaller insulin response area under the curve during $180 \mathrm{~min}$ of sampling [7,646 vs. $12,104 \pm 2,587(\mu \mathrm{IU} / \mathrm{mL}) \times 180 \mathrm{~min}$, reflecting an increased response to endogenous insulin. Based on literature, we do not expect NA to have altered glucose metabolism directly; therefore, this experiment demonstrates a cause and effect relationship between elevated NEFA and insulin resistance in Holstein cows.

Received February 24, 2007

Accepted May 2, 2007.

${ }^{1}$ Corresponding author: rgrummer@wisc.edu
Key words: nonesterified fatty acid, insulin resistance, nicotinic acid, bovine

\section{INTRODUCTION}

Elevated plasma NEFA concentration is a common feature in dairy cows during the periparturient period and reflects increased reliance on adipose reserves to support energy requirements and milk fat synthesis. However, exaggerated plasma NEFA concentration leads to triacylglycerol accumulation in muscle (Roberts et al., 1981) and liver (Roberts et al., 1981; Grummer, 1993) and is associated with depressed feed intake and metabolic disorders (Grummer, 1993).

Similarly, elevated plasma NEFA concentration causes triacylglycerol accumulation in muscle and liver of nonruminants and induces insulin resistance (Petersen and Shulman, 2006). In vitro incubation of 3T3$\mathrm{L} 1$ adipocytes with just $300 \mu \mathrm{Eq} / \mathrm{L}$ of palmitic acid (Van Epps-Fung et al., 1997) or linoleic acid (Gao et al., 2004) is sufficient to impair insulin-stimulated glucose uptake. Insulin resistance results from increased intracellular content of fatty acid metabolism intermediates, such as long-chain acyl-coenzyme A and diacylglycerol, which activate protein kinase $\mathrm{C}$ isoenzymes that phosphorylate inhibitory Ser residues of insulin substrate receptor-1, affecting downstream insulin-signaling events (Gao et al., 2004; Petersen and Shulman, 2006).

Insulin resistance in periparturient ruminants serves to prioritize glucogenic nutrients for vital functions, fetal growth, and lactose production and to enhance mobilization of fatty acids and glycerol from adipose tissue (Bell and Bauman, 1997). However, exaggerated insulin resistance in adipose tissue can potentially lead to further increases in plasma NEFA concentration and to the onset of metabolic disorders. Increased plasma NEFA concentration has been associated with insulin resistance in Holstein cows, but a direct link has yet to be demonstrated. For example, feed restriction impaired the response to insulin challenges in Holstein cows, and the degree of insulin resistance was correlated to NEFA concentration before the challenge (Oikawa and Oetzel, 2006). Overconditioned cows had sustained elevation of plasma NEFA postpar- 
tum, impaired clearance of glucose during i.v. glucose tolerance test (IVGTT), and greater insulin response when compared with cows calving with lower BCS (Holtenius et al., 2003). These results suggest an insulinresistant state mediated by elevated plasma NEFA concentration, adiposity, or both. We have shown that induction of hyperlipidemia by i.v. infusion of triacylglycerol emulsion causes insulin resistance in Holstein cows (Pires et al., 2007). The infusion of emulsion increased plasma NEFA, serum triacylglycerol, and glycerol, but we speculate the onset of insulin resistance was mediated by fatty acids derived from emulsion triacylglycerol, which enter the cells of peripheral tissues after lipolysis by lipoprotein lipase (Ferezou and Bach, 1999).

We have developed a model to induce differential concentrations of plasma NEFA in feed-restricted cows, using nicotinic acid (NA) as an antilipolytic agent (Pires and Grummer, 2007). This approach allows us to test for a cause-effect relationship between elevated NEFA and insulin resistance in Holstein cows. In the present experiment, we hypothesized that increased plasma NEFA concentration causes insulin resistance in Holstein cows; therefore, reducing plasma NEFA in feedrestricted cows would enhance their response to insulin.

\section{MATERIALS AND METHODS}

\section{Animals and Treatments}

Six nonlactating, nongestating ruminally cannulated Holstein cows were blocked by BCS $(4.0 \pm 0.4$, mean \pm SD; NRC, 2001) and randomly assigned to a sequence of 2 treatments in a crossover design. Twelve days were allowed between experimental periods to avoid potential carryover effects. For logistical reasons, animals were divided in 2 groups, each starting the experimental protocol 1 wk apart.

Cows were fed legume and grass hay ad libitum supplemented with minerals and vitamins to meet or exceed NRC recommendations (NRC, 2001). Feed was provided twice daily, except during feed restriction. Animals were allowed free access to water and a trace mineralized salt block throughout the experiment. Mobilization of body reserves and the consequent increase in plasma NEFA concentration were stimulated by withdrawing forage for $48 \mathrm{~h}$ before the infusion of treatments. During feed restriction, cows were supplemented daily with vitamins and minerals that were mixed with wheat middlings as a carrier (total of $1 \mathrm{~kg}$ / d) to meet requirements (NRC, 2001). Body weight (786 $\pm 36 \mathrm{~kg}$; mean $\pm \mathrm{SD}$ ) was recorded on the day before initiation of each period, 5 to $6 \mathrm{~h}$ after morning feed was offered and was used to calculate individual treatment and glucose doses.
Administration of treatments started $48 \mathrm{~h}$ after initiation of feed restriction and consisted of 11 hourly abomasal infusions of $1 \mathrm{~L}$ of water (control) or the same volume of NA solution at a rate of $6 \mathrm{mg}$ of NA/h per kilogram of BW. Nicotinic acid (99.7\% purity; Adisseo USA Inc., Alpharetta, GA) was diluted in water with equimolar amounts of sodium bicarbonate to facilitate solubilization. The rate of NA infusion was based on a methodology to induce sustained reductions of plasma NEFA concentration in feed-restricted cows (Pires and Grummer, 2007). Cows were rumen-cannulated to allow infusion of treatments into the abomasum (Gressley et al., 2006) and to prevent ruminal degradation of NA. Each hourly dose was infused over approximately 1 $\min$.

\section{IVGTT and Blood Sampling}

Catheters (polyurethane 14-gauge $\times 13 \mathrm{~cm}$; MILA International Inc., Erlanger, KY) were fitted into the right jugular vein of each cow and attached to an extension set (Baxter International Inc., Deerfield, IL; $86 \mathrm{~cm}$, 3.9-mL vol.) on the day before IVGTT. Patency was maintained by flushing catheters with $8 \mathrm{~mL}$ of heparinized saline (100 IU/mL) every $8 \mathrm{~h}$ or with diluted heparinized saline $(10 \mathrm{IU} / \mathrm{mL})$ during frequent sampling. Cows were given 10,000 IU of penicillin G/d per kilogram of BW (G. C. Hanford Manufacturing Co., Syracuse, NY) following the insertion of catheters as a prophylactic procedure.

Intravenous glucose tolerance test was performed 8 $\mathrm{h}$ after initiation of infusions by administering $0.25 \mathrm{~g} /$ $\mathrm{kg}$ of BW of glucose i.v. (dextrose $50 \%$ wt/vol; Phoenix Scientific Inc., St. Joseph, MO) over $4.3 \pm 0.4$ min (mean $\pm \mathrm{SD}$ ), followed by $50 \mathrm{~mL}$ of sterile saline to flush catheters and prevent contamination of subsequent samples. A 14-gauge catheter was chosen to facilitate the flow of glucose and shorten the duration of infusion. Treatments were applied for $8 \mathrm{~h}$ before IVGTT to allow comparison of results with a previous experiment in which hyperlipidemia was induced by i.v. infusion of lipid emulsion (Pires et al., 2007).

Blood samples were collected at 0 and $24 \mathrm{~h}$ of feed restriction, before each abomasal infusion, and at -15 , $-5,7,10,15,20,30,40,50,60,75,90,120,150$, and $180 \mathrm{~min}$ relative to administration of glucose. Hourly infusion of treatments continued throughout the $3 \mathrm{~h}$ of IVGTT sampling.

\section{Estrous Synchronization}

Estrous cycle was synchronized each period using an intravaginal progesterone-releasing device (controlled internal drug release containing $1.38 \mathrm{~g}$ of progesterone; 
Eazi-Breed, Hamilton, New Zealand) for $7 \mathrm{~d}$, administration of $\mathrm{PGF}_{2 \alpha}$ (Lutalyse, $25 \mathrm{mg}$; Pfizer Animal Health, Kalamazoo, MI), and aspiration of ovarian follicles with a diameter greater than $5 \mathrm{~mm}$ on the day before IVGTT, as previously described and validated (Pires et al., 2007). This protocol induces low concentrations of progesterone and estradiol across treatments and experimental periods and reduces potential interference of reproductive hormones with IVGTT.

\section{Blood Plasma and Serum Analysis}

Blood was drawn by venipucture from the coccygeal vein or artery using Vacutainer tubes (Becton Dickinson, Franklin Lakes, NJ) or from catheters using disposable 20-mL syringes. Tubes for collection of plasma (6 mL; containing $12 \mathrm{mg}$ of potassium oxalate and 15 $\mathrm{mg}$ of sodium fluoride as a glycolytic inhibitor) were kept on ice until centrifugation at $920 \times g$ at $4^{\circ} \mathrm{C}$ for 20 min. For collection of serum, tubes $(6 \mathrm{~mL}$; containing clot activator) were allowed to clot at room temperature and centrifuged at $2,050 \times \mathrm{g}$ at $20^{\circ} \mathrm{C}$ for $30 \mathrm{~min}$.

Blood plasma was analyzed for glucose and NEFA, and serum was analyzed for insulin as described previously (Pires et al., 2007). Intra- and interassay CV were 2.7 and $3.0 \%$ for glucose, 3.2 and $3.4 \%$ for NEFA, and 4.2 and $8.6 \%$ for insulin, respectively.

\section{Calculations and Statistical Analysis}

Statistical analysis was preformed using SAS version 9.1 (SAS Institute Inc., Cary, NC). Glucose clearance $(\% / \mathrm{min})$, time to reach half-concentration (min), time to reach basal concentration (min), and area under the curve during the first 60,120 , and 180 min of IVGTT were calculated as previously described (Pires et al., 2007). Basal glucose and insulin concentrations were calculated by averaging values from samples taken 15 and 5 min before IVGTT.

The IVGTT measurements were analyzed using the MIXED procedure of SAS. The model included the fixed effects of treatment and sequence and the random effects of period and cow within sequence. Group was initially included in the model for all variables but was removed, because it was not significant $(P>0.40)$. For blood metabolites and insulin, time and treatment $x$ time interaction were added to the model and were analyzed using repeated measures in time with Kenward-Rogers adjustment for calculation of denominator degrees of freedom. First-order autoregressive covariance structure was used for data collected before glucose infusion for IVGTT; spatial power covariance structure was used for data collected thereafter to allow for unequal sampling intervals. Heterogeneous variance
Table 1. Effects of feed restriction on blood metabolites

\begin{tabular}{|c|c|c|c|c|c|}
\hline \multirow[b]{2}{*}{ Item } & \multicolumn{3}{|c|}{ Time of feed restriction } & \multirow[b]{2}{*}{ SEM } & \multirow[b]{2}{*}{$P$} \\
\hline & $0 \mathrm{~h}$ & $24 \mathrm{~h}$ & $48 \mathrm{~h}$ & & \\
\hline NEFA $(\mu \mathrm{Eq} / \mathrm{L})$ & $134^{\mathrm{c}}$ & $478^{\mathrm{b}}$ & $545^{\mathrm{a}}$ & 32 & $<0.001$ \\
\hline Glucose (mg/dL) & 63.4 & 62.7 & 61.3 & 1.9 & 0.19 \\
\hline Insulin $(\mu \mathrm{IU} / \mathrm{mL})$ & $23.8^{\mathrm{a}}$ & $15.0^{\mathrm{b}}$ & $11.3^{\mathrm{c}}$ & 1.8 & $<0.001$ \\
\hline
\end{tabular}

across treatments was used whenever it provided a better fit according to Schwarz's Bayesian criterion.

Values reported are least squares means and SEM, unless otherwise stated. To comply with the assumptions of normality and homoscedacity of residuals, logarithmic transformation was used for the statistical analysis of insulin concentration during the first $8 \mathrm{~h}$ of treatments and IVGTT and for insulin area under the curve in response to glucose infusion. For these variables, least squares means and SEM were derived from untransformed values, whereas $P$-values reflect statistical analysis of transformed data.

The significance level for treatment effects on IVGTT parameters was predefined at $P \leq 0.10$ and a trend toward significance defined at $0.10<P<0.15$. To reduce risk of type I error for repeated measures analysis, the significance level was decreased to $P \leq 0.05$, and trends toward significance were considered at $0.05<P \leq 0.10$. Treatment differences at individual time points were assessed using the SLICE option when treatment $x$ time interaction was significant.

\section{RESULTS AND DISCUSSION}

\section{Effect of Feed Restriction on Blood Metabolites and Insulin}

Feed restriction increased $(P<0.001)$ plasma NEFA concentration from 134 to $545 \mu \mathrm{Eq} / \mathrm{L}$ at $48 \mathrm{~h}$ of feed restriction (Table 1). Insulin concentration decreased $(P<0.001)$ to less than one-half of the prefasting value, with no changes on plasma glucose concentration.

\section{Effect of Treatments on Blood Metabolites and Insulin (First 8 h)}

Infusion of NA caused a sustained reduction in plasma NEFA concentration (segment A in Figure 1), leading to significant treatment, time, and treatment $\times$ time effects $(P<0.001)$. Plasma NEFA concentration decreased, from an average of $545 \mu \mathrm{Eq} / \mathrm{L}$ immediately before initiation of treatments, to approximately 100 $\mu \mathrm{Eq} / \mathrm{L}$ within $2 \mathrm{~h}$ after initiation of NA infusions. Eight hours after the beginning of infusions, immediately before initiation of IVGTT, plasma NEFA concentrations 


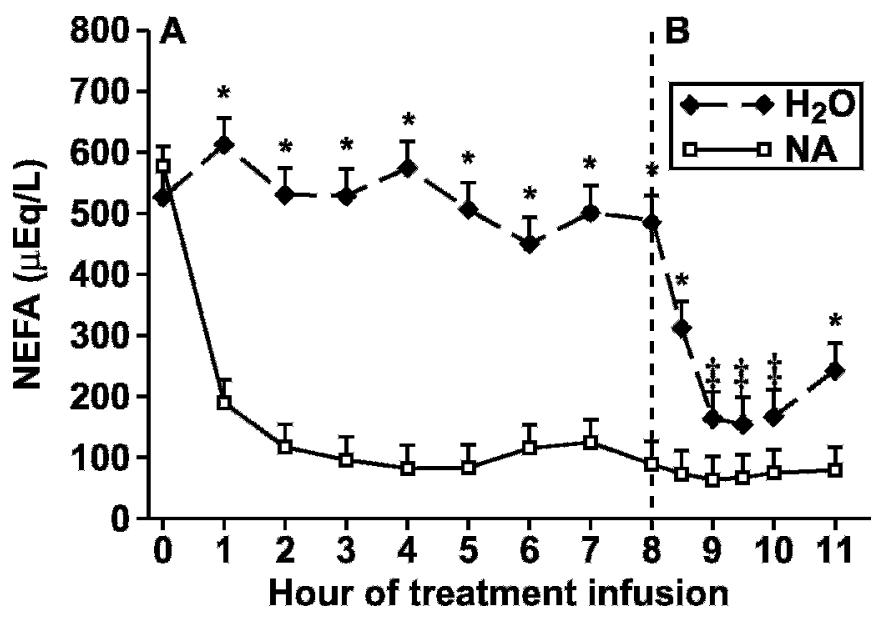

Figure 1. Effects of abomasal infusions of water (control) or nicotinic acid (NA; $6 \mathrm{mg} / \mathrm{h}$ per $\mathrm{kg}$ of BW) on plasma NEFA concentration in feed-restricted Holstein cows before (A) and during i.v. glucose tolerance test (IVGTT; B). Infusion of treatments started $48 \mathrm{~h}$ after initiation of feed restriction (time 0 ) and was repeated at 1, 2, 3, 4, $5,6,7,8,9$, and $10 \mathrm{~h}$. The IVGTT $(0.25 \mathrm{~g} / \mathrm{kg}$ of BW of glucose i.v.) was performed $8 \mathrm{~h}$ after initiation of treatments. Fixed effects in the statistical model: sequence $(P=0.96)$, treatment $(P<0.001)$, time $(P$ $<0.001)$, and treatment $\times$ time $(P<0.001)$. Treatment differences within a time point are indicated by $*(P<0.001)$ and $\ddagger(P<0.05)$.

were $87 \pm 37$ and $487 \pm 42 \mu \mathrm{Eq} / \mathrm{L}(P<0.001)$ for NA and control, respectively. The decrease in plasma NEFA concentration followed the pattern observed previously (Pires and Grummer, 2007) and confirm the repeatability of this protocol.

Nicotinic acid at supraphysiologic concentrations inhibits lipolysis and reduces plasma NEFA concentration, because it binds to NA receptors that are highly expressed in adipose tissue. Binding of NA activates an inhibitory $\mathrm{G}$ protein and reduces cytoplasmic cyclic AMP (cAMP) concentration, which decreases hormonesensitive lipase activity (Carlson, 2005). The antilipolytic action of NA may result from a negative feedback mechanism to prevent excessive mobilization of fatty acids during periods of negative energy balance because D-BHBA at physiologic concentrations is a natural ligand of the NA receptor (Taggart et al., 2005). It has been shown that incubation of bovine adipose tissue explants with BHBA inhibits lipolysis through a cAMPdependent mechanism (Metz et al., 1974).

There was a trend for treatment $\times$ time interaction $(P=0.07)$ for glucose concentration during the first 8 $\mathrm{h}$ of infusions (Figure 2). Plasma glucose averaged 62.0 \pm 2.9 and $51.6 \pm 2.3 \mathrm{mg} / \mathrm{dL}$ for NA and control, respectively. During this period, there were significant treatment $(P=0.01)$ and time $(P=0.01)$ effects and a trend for treatment $\times$ time interaction $(P=0.08)$ for serum insulin concentration (Figure 3 ). Insulin concentration was lower $(P=0.01)$ for NA than for control, averaging

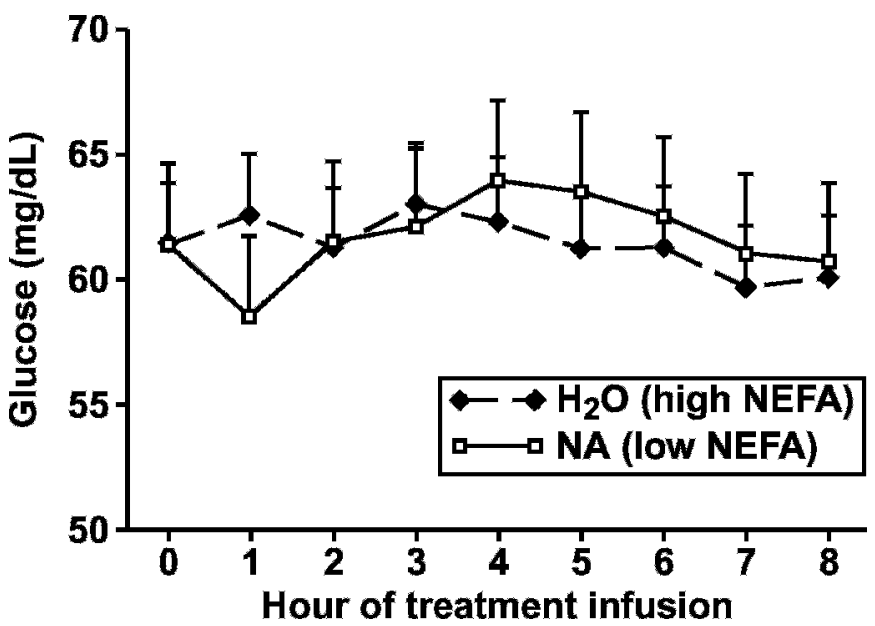

Figure 2. Effects of abomasal infusions of water (control) or nicotinic acid (NA; $6 \mathrm{mg} / \mathrm{h}$ per $\mathrm{kg}$ of $\mathrm{BW}$ ) on plasma glucose in feedrestricted Holstein cows before i.v. glucose tolerance test (IVGTT). Nicotinic acid was used as an antilipolytic agent to induce low plasma nonesterified acid concentrations. Infusion of treatments started 48 $\mathrm{h}$ after initiation of feed restriction (time 0 ) and was repeated at 1 , $2,3,4,5,6,7,8,9$, and $10 \mathrm{~h}$. The IVGTT $(0.25 \mathrm{~g} / \mathrm{kg}$ of BW of glucose i.v.) was performed $8 \mathrm{~h}$ after initiation of treatments. Fixed effects in the statistical model: sequence $(P=0.40)$, treatment $(P=0.90)$, time $(P=0.20)$, and treatment $\times$ time $(P=0.07)$.

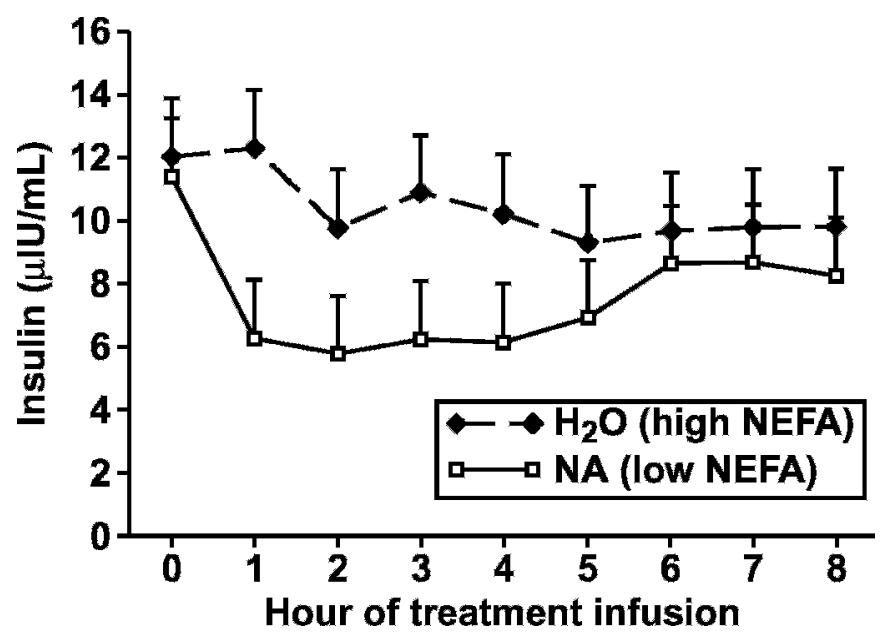

Figure 3. Effects of abomasal infusions of water (control) or nicotinic acid (NA; $6 \mathrm{mg} / \mathrm{h}$ per $\mathrm{kg}$ of $\mathrm{BW}$ ) on serum insulin in feed-restricted Holstein cows before i.v. glucose tolerance test (IVGTT). Nicotinic acid was used as an antilipolytic agent to induce low plasma nonesterified acid concentrations. Infusion of treatments started $48 \mathrm{~h}$ after initiation of feed restriction (time 0 ) and was repeated at $1,2,3,4$, $5,6,7,8,9$, and $10 \mathrm{~h}$. The IVGTT $(0.25 \mathrm{~g} / \mathrm{kg}$ of BW of glucose i.v.) was performed $8 \mathrm{~h}$ after initiation of treatments. Fixed effects in the statistical model: sequence $(P=0.90)$, treatment $(P=0.01)$, time $(P=$ $0.01)$, and treatment $\times$ time $(P=0.08)$. The $P$-values reflect statistical analysis with logarithm-transformed data to comply with the assumptions of normality and homoscedacity of residuals. 
Table 2. Effects of abomasal infusions of water or nicotinic acid (NA; $6 \mathrm{mg} / \mathrm{h}$ per $\mathrm{kg}$ of BW) on i.v. glucose tolerance test (IVGTT) measurements ${ }^{1}$

\begin{tabular}{lcccc}
\hline Item & $\begin{array}{c}\mathrm{H}_{2} \mathrm{O} \\
\text { (high NEFA) }\end{array}$ & $\begin{array}{c}\text { NA } \\
\text { (low NEFA) }\end{array}$ & SEM & $P$ \\
\hline Basal NEFA $^{2}$ & 487 & 87 & 42 & $<0.001$ \\
Basal glucose $^{3}$ & 60.6 & 61.3 & 3.0 & 0.79 \\
Basal insulin $^{4}$ & 9.5 & 9.3 & 2.3 & 0.91 \\
$\mathrm{CR}^{5}$ & 1.22 & 1.94 & 0.13 & $<0.01$ \\
$\mathrm{~T}_{1 / 2}{ }^{6}$ & 58.1 & 36.6 & 4.4 & $<0.001$ \\
$\mathrm{~T}_{\text {basal }}{ }^{7}$ & 114.3 & 80.9 & 6.5 & $<0.001$ \\
AUC $_{60}{ }^{9}$ & 5,934 & 5,628 & 212 & 0.18 \\
AUC $_{120}{ }^{10}$ & 8,811 & 6,774 & 362 & $<0.01$ \\
AUC $_{180}{ }^{10}$ & 10,085 & 6,942 & 408 & 0.001 \\
\hline
\end{tabular}

${ }^{1}$ Infusion of treatments started $48 \mathrm{~h}$ after initiation of feed restriction (time 0 ) and was repeated at $1,2,3,4,5,6,7,8,9$, and $10 \mathrm{~h}$. The IVGTT $(0.25 \mathrm{~g} / \mathrm{kg}$ of BW of glucose i.v.) was performed $8 \mathrm{~h}$ after initiation of treatments. L.

${ }^{2}$ Nonesterified fatty acid concentration 5 min before IVGTT, $\mu \mathrm{Eq} /$ dL.

${ }^{3}$ Mean glucose concentration at 15 and 5 min before IVGTT, mg/

${ }^{4}$ Mean insulin concentration at 15 and 5 min before IVGTT, $\mu$ IU/ $\mathrm{mL}$.

${ }^{5}$ Glucose clearance rate during the first $60 \mathrm{~min}$ of IVGTT (\%/min).

${ }^{6}$ Time to reach $1 / 2$ of glucose concentration ( $\mathrm{min}$ ).

${ }^{7}$ Time to reach basal glucose concentration (min).

${ }^{8}$ Area under the curve during the first $60 \mathrm{~min}$ of IVGTT, $(\mathrm{mg} / \mathrm{dL})$ $\times 60 \mathrm{~min}$.

${ }^{9}$ Area under the curve during the first $120 \mathrm{~min}$ of IVGTT, $(\mathrm{mg} / \mathrm{dL})$ $\times 120$ min.

${ }^{10}$ Area under the curve during the first $180 \mathrm{~min}$ of IVGTT, (mg/ dL) $\times 180 \mathrm{~min}$.

$7.6 \pm 1.3$ and $10.6 \pm 1.6 \mu \mathrm{IU} / \mathrm{mL}$, respectively. However, there were no treatment differences for glucose and insulin concentrations $8 \mathrm{~h}$ after initiation of treatments, immediately before infusion of glucose for IVGTT (Table 2).

The shifts in insulin and glucose concentrations after initiation of treatment infusion probably reflect metabolic adaptations to the rapid decline in plasma NEFA induced by NA (segment A in Figure 1). Maintenance of glucose concentration during infusion of treatments may have been achieved by enhanced glycogenolysis and increased gluconeogenesis from AA.

\section{Effect of Treatments on Responses to IVGTT}

Nonesterified fatty acid concentration decreased sharply after the infusion of glucose for IVGTT when cows received control treatment (segment B in Figure 1). This effect was due to the antilipolytic action of insulin secreted in response to i.v. glucose infusion (Figure 4). In contrast, there were only minimal effects of IVGTT on plasma NEFA when cows received NA (segment B in Figure 1), suggesting that the rate of infusion of NA caused maximal inhibition of lipolysis,

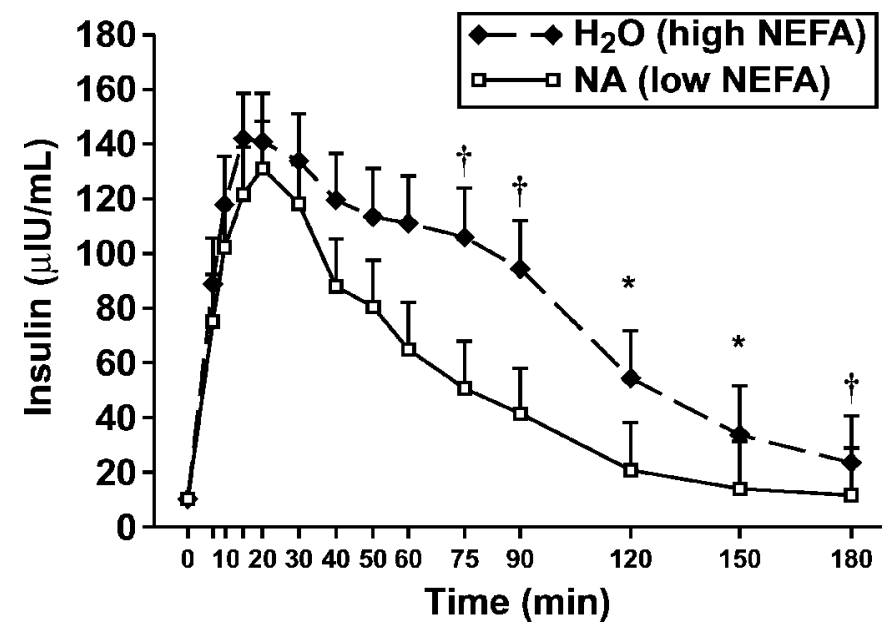

Figure 4. Effects of abomasal infusions of water (control) or nicotinic acid (NA; $6 \mathrm{mg} / \mathrm{h}$ per $\mathrm{kg}$ of $\mathrm{BW}$ ) on insulin concentration during i.v. glucose tolerance test (IVGTT). Nicotinic acid was used as an antilipolytic agent to induce low plasma nonesterified acid concentrations. Infusion of treatments started $48 \mathrm{~h}$ after initiation of feed restriction (time 0 ) and was repeated at $1,2,3,4,5,6,7,8,9$, and $10 \mathrm{~h}$. The IVGTT $(0.25 \mathrm{~g} / \mathrm{kg}$ of BW of glucose i.v.) was performed 8 $\mathrm{h}$ after initiation of treatments. Fixed effects in the statistical model for the analysis of insulin concentration after infusion of glucose: sequence $(P=0.40)$, treatment $(P=0.05)$, time $(P<0.001)$, and treatment $\times$ time $(P=0.02)$. Treatment differences within a time point are indicated by $*(P<0.001)$ and $\dagger(P<0.01)$. The $P$-values reflect statistical analysis with logarithm-transformed data to comply with the assumptions of normality and homoscedacity of residuals.

as previously observed (Pires and Grummer, 2007). Plasma NEFA concentration was lower $(P<0.05)$ for NA than control during the $3 \mathrm{~h}$ of IVGTT sampling.

There were treatment $(P=0.02)$, time, and treatment $\times$ time effects $(P<0.001)$ for glucose concentration during IVGTT (Figure 5). Glucose concentration was greater $(P<0.05)$ for NA than control until $10 \mathrm{~min}$ after glucose infusion but declined at a faster rate, leading to lower $(P<0.05)$ glucose concentration at $40 \mathrm{~min}$ of IVGTT and thereafter. Therefore, reducing plasma NEFA concentration with abomasal infusions of NA significantly increased glucose clearance, decreasing time to reach half-concentration, time to reach basal concentration, and area under the curve during the first 120 and 180 min of IVGTT (Table 2).

There were treatment $(P=0.05)$, time $(P<0.001)$, and treatment $\times$ time effects $(P=0.02)$ for glucose concentration during IVGTT (Figure 5). Serum insulin concentration after infusion of glucose was lower $(P=0.05)$ for NA than control (70.0 vs. $97.9 \pm 13.4 \mu \mathrm{IU} / \mathrm{mL})$. Insulin area under the curve during the first $180 \mathrm{~min}$ of IVGTT tended to be lower $(P=0.11)$ when cows received NA [7,646 vs. $12,104 \pm 2,587(\mu \mathrm{IU} / \mathrm{mL}) \times 180 \mathrm{~min}]$. Insulin area under the curve during the first $60 \mathrm{~min}$ of IVGTT was 5,152 and $6,012 \pm 1,583(\mu \mathrm{IU} / \mathrm{mL}) \times 60 \mathrm{~min}$ 


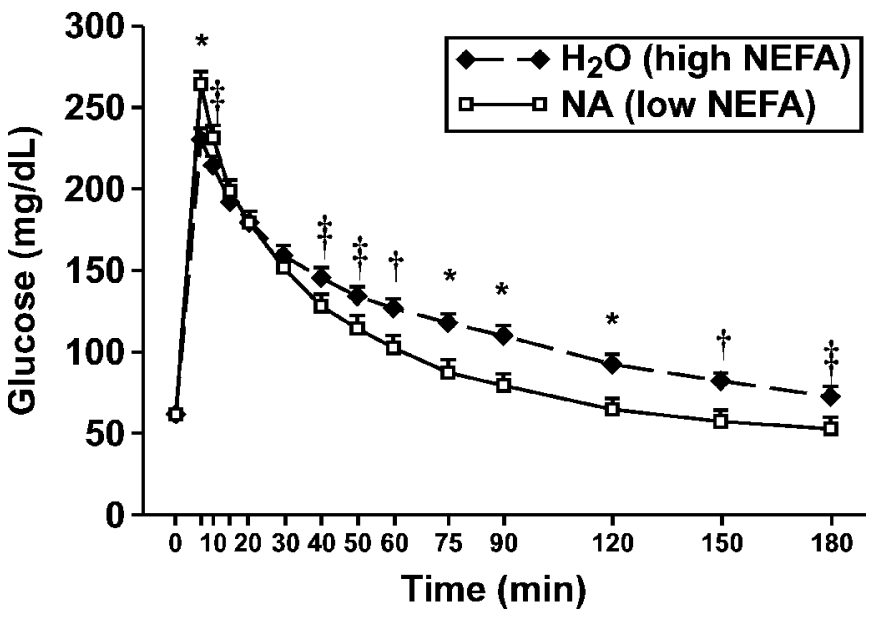

Figure 5. Effects of abomasal infusions of water (control) or nicotinic acid (NA; $6 \mathrm{mg} / \mathrm{h}$ per $\mathrm{kg}$ of $\mathrm{BW}$ ) on glucose clearance during i.v. glucose tolerance test (IVGTT). Nicotinic acid was used as an antilipolytic agent to induce low plasma nonesterified acid concentrations. Infusion of treatments started $48 \mathrm{~h}$ after initiation of feed restriction (time 0 ) and was repeated at $1,2,3,4,5,6,7,8,9$, and $10 \mathrm{~h}$. The IVGTT $(0.25 \mathrm{~g} / \mathrm{kg}$ of BW of glucose i.v.) was performed 8 $\mathrm{h}$ after initiation of treatments. Fixed effects in the statistical model for the analysis of glucose concentration after IVGTT: sequence $(P=$ $0.15)$, treatment $(P=0.02)$, time $(P<0.001)$, and treatment $\times$ time $(P<0.001)$. Treatment differences within a time point are indicated by $*(P<0.001), \dagger(P<0.01)$, and $\dagger(P<0.05)$.

$(P=0.88)$, and area under the curve during the first 120 min of IVGTT was 7,223 and 10,575 $\pm 2,482$ ( $\mu \mathrm{IU} /$ $\mathrm{mL}) \times 120 \mathrm{~min}(P=0.21)$ for NA and control, respectively.

We have previously shown that $8 \mathrm{~h}$ of hyperlipidemia, caused by i.v. infusion of triacylglycerol emulsion, impaired responses to IVGTT and insulin challenges in Holstein cows (Pires et al., 2007). The results from the present experiment directly implicate NEFA on the induction of insulin resistance, because lowering $(P<$ 0.001) plasma NEFA concentration in feed-restricted cows enhanced $(P<0.01)$ clearance of glucose during IVGTT. This occurred despite lower $(P=0.05)$ insulin concentration, which reflects an increased response to endogenous insulin. Clearance of glucose during IVGTT is a function of glucose uptake and insulin-mediated inhibition of endogenous glucose production. The reduction of plasma NEFA may have enhanced glucose utilization, inhibited endogenous glucose production, or both, by increasing insulin sensitivity.

Our results are supported by studies in humans involving the use of acipimox, a long-acting NA analog that inhibits lipolysis by the same mechanism of NA (Christie et al., 1996). Acute (Vaag et al., 1991), overnight (Santomauro et al., 1999), and long-term (Bajaj et al., 2005) reduction of plasma NEFA with acipimox led to improved response to oral glucose tolerance tests
(Santomauro et al., 1999) and enhanced insulin-stimulated glucose utilization by peripheral tissues during hyperinsulinemic euglycemic clamps (Vaag et al., 1991; Santomauro et al., 1999; Bajaj et al., 2005). The degree of increase in insulin sensitivity in peripheral tissues after treatment with acipimox is correlated to the magnitude of decrease in plasma NEFA concentration (Santomauro et al., 1999; Bajaj et al., 2005) and long-chain fatty acyl-coenzyme A content in muscle (Bajaj et al., 2005), implicating elevated plasma NEFA and its intracellular-derived metabolites in the establishment of insulin-resistant states.

Nicotinic acid acts in adipocytes by reducing intracellular cAMP (Karpe and Frayn, 2004; Carlson, 2005), therefore, a direct action of NA on glucose metabolism is conceivable. However, we expect NA to have altered the responses to IVGTT indirectly through its antilipolytic effect and reduction of plasma NEFA concentration. For instance, treatment with acipimox and concomitant stabilization of plasma NEFA concentration, to test for direct effects of NA analog on glucose metabolism, did not affect glucose disposal (Davoren et al., 1995) nor insulin-induced suppression of hepatic glucose production (Saloranta et al., 1991) in type 2 diabetic humans. Large NA boluses cause transient reduction of plasma NEFA followed by a dramatic rebound (Waterman et al., 1972; Pires and Grummer, 2007). Earlier studies found unexplained impairment of glucose tolerance and reduced response to exogenous insulin in ruminants during NA-induced NEFA rebound (Thornton and Schultz, 1980). These results further support a direct role of NEFA on the development of insulin resistance.

It has been shown that overconditioned periparturient dairy cows are more insulin resistant than cows with lower BCS (Holtenius et al., 2003). Overnight reduction of NEFA normalized insulin sensitivity in obese nondiabetic humans, implicating elevated plasma NEFA concentration as a mediator of insulin resistance in obesity (Santomauro et al., 1999). Cows in our experiment were overconditioned, with BCS ranging from 3.5 to 4.5. Based on research in nonruminants previously discussed, we expect that lowering plasma NEFA will improve the response to insulin in cows with a normal BCS, but potential interactions between plasma NEFA and insulin resistance at different physiological states deserve further investigation in the dairy cow.

Our results raise questions about the effectiveness of protocols for treatment of clinical ketosis, which commonly involve i.v. infusion of glucose (Hove, 1978; Sakai et al., 1993; Bigner et al., 1996). The uptake of glucose by peripheral tissues may be affected in ketotic cows, because these animals have impaired insulin secretion in response to i.v. glucose infusion (Hove, 1978; Sakai 
et al., 1993) and can present NEFA concentrations over $1,300 \mu \mathrm{Eq} / \mathrm{L}$ (Sakai et al., 1993), which would lead to NEFA-induced insulin resistance. Therefore, our data support the concept that treatment of ketosis should involve concomitant administration of insulin to overcome the limited insulin secretion (Sakai et al., 1993) and NEFA-induced insulin resistance.

Administration of NA has been suggested for the treatment of ketosis due to its antilipolytic properties (Waterman et al., 1972; Fronk and Schultz, 1979). However, the occurrence of NEFA rebound after large doses of NA can potentially aggravate fatty liver, ketone production, and insulin resistance (Pires and Grummer, 2007). Furthermore, feed intake was depressed during NA-induced NEFA rebound to a degree related to the magnitude of NEFA elevation (Thornton and Schultz, 1980). Before NA can be used to prevent or treat ketosis, a proper rate of NA administration must be found to induce sustained decreases in plasma NEFA. Alternatively, long-acting NA analogs, such as acipimox, could be applied to lower plasma NEFA, but to our knowledge, these compounds have not been tested in ruminants.

We have assessed the relationship between elevated plasma NEFA and insulin resistance by measuring the effects of changes in plasma NEFA on glucose clearance during IVGTT. Glucose uptake is the rate-limiting step in glucose utilization, and it involves the facilitative glucose transporter GLUT4 in insulin responsive tissues, such as skeletal muscle and adipose tissue, whereas placenta and mammary gland express glucose transporters that are independent of insulin (Hocquette and Abe, 2000). Ruminant muscle and adipose tissue are less responsive to insulin than in other species, probably as an adaptative strategy to spare glucose, because little glucose is absorbed by the intestine, and ruminants rely on gluconeogenesis (Bell and Bauman, 1997; Hocquette and Abe, 2000). Late gestation and onset of lactation are characterized by further development of insulin resistance, due to postreceptor modifications of insulin signaling and a decrease in GLUT4 protein content in muscle and adipose (Bell and Bauman, 1997; Hocquette and Abe, 2000). Establishment of insulin resistance is an important homeorhetic regulator of nutrient partitioning in periparturient ruminants that is mediated by growth hormone and possibly other regulators that have not been identified (Bell and Bauman, 1997). Our experiment implicates plasma NEFA as a causal factor in insulin resistance in dairy cows during periods of negative energy balance. Induction of insulin resistance by NEFA will further shift glucose utilization to the fetus during late gestation and to the mammary gland, which is responsible for up to $80 \%$ of glucose utilization in cows during peak lactation (Bell and Bauman, 1997).
Insulin controls a wide array of cell functions, from glucose and lipid metabolism to AA uptake, protein synthesis, and gene expression (Cheatham and Kahn, 1995). We expect NEFA-induced insulin resistance to affect cell functions beyond glucose metabolism, because elevated plasma NEFA interferes with early steps of insulin-signaling cascade (Gao et al., 2004; Petersen and Shulman, 2006). For instance, induction of supraphysiologic hyperlipidemia in rats decreased basal protein synthesis, altered intracellular regulators of protein translation, and induced resistance to IGFI (Lang, 2006).

\section{CONCLUSIONS}

We have confirmed the repeatability of a protocol to induce differential concentrations of plasma NEFA in feed-restricted cows, employing NA as an antilipolytic agent (Pires and Grummer, 2007). Using this protocol, we have shown that lowering plasma NEFA concentration enhances the response to insulin in feed-restricted Holstein cows, implicating plasma NEFA as a causal factor of insulin resistance.

These findings support a role for elevated plasma NEFA as a homeorhetic regulator in periparturient dairy cows. Insulin resistance in the periparturient period may help sparing of glucogenic nutrients (Bell and Bauman, 1997). However, the effect of NEFA-induced insulin resistance in the periparturient dairy cow will depend on the magnitude and on which tissues become insulin resistant. For instance, exaggerated insulin resistance in adipose tissue may potentially enhance the rate of lipolysis, further increasing plasma NEFA and the risk of metabolic disorders. Impaired insulin signaling due to elevated NEFA may affect an array of cell functions in different tissues, with important repercussions on the physiology and productivity of the periparturient dairy cow.

\section{ACKNOWLEDGMENTS}

We thank University of Wisconsin-Madison dairy nutrition students and staff for help during sample collection and processing, to A. P. Cunha and J. N. Guenther for performing follicular aspirations, and to the staff at the Dairy Cattle Instruction and Research Center for animal care and feeding. We appreciate the donation of NA from Vitaplus Corp., Madison, Wisconsin. J. A. A. Pires gratefully acknowledges a fellowship (SFRH/ BD/9915/2002) from Fundação para a Ciência e a Tecnologia (Lisbon, Portugal).

\section{REFERENCES}

Bajaj, M., S. Suraamornkul, A. Romanelli, G. W. Cline, L. J. Mandarino, G. I. Shulman, and R. A. DeFronzo. 2005. Effect of a sus- 
tained reduction in plasma free fatty acid concentration on intramuscular long-chain fatty acyl-CoAs and insulin action in type 2 diabetic patients. Diabetes 54:3148-3153.

Bell, A. W., and D. E. Bauman. 1997. Adaptations of glucose metabolism during pregnancy and lactation. J. Mammary Gland Biol. Neoplasia 2:265-278.

Bigner, D. R., J. P. Goff, M. A. Faust, J. L. Burton, H. D. Tyler, and R. L. Horst. 1996. Acidosis effects on insulin response during glucose tolerance tests in Jersey cows. J. Dairy Sci. 79:2182-2188.

Carlson, L. A. 2005. Nicotinic acid: The broad-spectrum lipid drug. A 50th anniversary review. J. Intern. Med. 258:94-114.

Cheatham, B., and C. R. Kahn. 1995. Insulin action and the insulin signaling network. Endocr. Rev. 16:117-142.

Christie, A. W., D. K. T. McCormick, N. Emmison, F. B. Kraemer, K. G. M. M. Alberti, and S. J. Yeaman. 1996. Mechanism of antilipolytic action of acipimox in isolated rat adipocytes. Diabetologia 39:45-53.

Davoren, P. M., A. Motala, and K. Alberti. 1995. The effect of acipimox on glucose disposal in non-insulin-dependent diabetes is dependent on the lowering of nonesterified fatty-acid levels. Diabetes Nutr. Metab. 8:99-104.

Ferezou, J., and A. C. Bach. 1999. Structure and metabolic fate of triacylglycerol- and phospholipid-rich particles of commercial parenteral fat emulsions. Nutrition 15:44-50.

Fronk, T. J., and L. H. Schultz. 1979. Oral nicotinic acid as a treatment for ketosis. J. Dairy Sci. 62:1804-1807.

Gao, Z., X. Zhang, A. Zuberi, D. Hwang, M. J. Quon, M. Lefevre, and J. Ye. 2004. Inhibition of insulin sensitivity by free fatty acids requires activation of multiple serine kinases in 3T3-L1 adipocytes. Mol. Endocrinol. 18:2024-2034.

Gressley, T. F., S. M. Reynal, J. J. O. Colmenero, G. A. Broderick, and L. E. Armentano. 2006. Technical note: Development of a tool to insert abomasal infusion lines into dairy cows. J. Dairy Sci. 89:3965-3967.

Grummer, R. R. 1993. Etiology of lipid-related metabolic disorders in periparturient dairy cows. J. Dairy Sci. 76:3882-3896.

Hocquette, J. F., and H. Abe. 2000. Facilitative glucose transporters in livestock species. Reprod. Nutr. Dev. 40:517-533.

Holtenius, K., S. Agenas, C. Delavaud, and Y. Chilliard. 2003. Effects of feeding intensity during the dry period. 2. Metabolic and hormonal responses. J. Dairy Sci. 86:883-891.

Hove, K. 1978. Insulin-secretion in lactating cows-Responses to glucose infused intravenously in normal, ketonemic, and starved animals. J. Dairy Sci. 61:1407-1413.

Karpe, F., and P. K. N. Frayn. 2004. The nicotinic acid receptor-A new mechanism for an old drug. Lancet 363:1892-1894.

Lang, C. H. 2006. Elevated plasma free fatty acids decrease basal protein synthesis, but not the anabolic effect of leucine, in skeletal muscle. Am. J. Physiol. Endocrinol. Metab. 291:E666-E674.
Metz, S. H., M. Lopes-Cardozo, and S. G. van den Bergh. 1974. Inhibition of lipolysis in bovine adipose-tissue by butyrate and $\beta$-hydroxybutyrate. FEBS Lett. 47:19-22.

NRC. 2001. Nutrient Requirements of Dairy Cattle. 7th rev. ed. Natl. Acad. Press, Washington, DC.

Oikawa, S., and G. R. Oetzel. 2006. Decreased insulin response in dairy cows following a four-day fast to induce hepatic lipidosis. J. Dairy Sci. 89:2999-3005.

Petersen, F. K., and G. I. Shulman. 2006. New insights into the pathogenesis of insulin resistance in humans using magnetic resonance spectroscopy. Obesity 14:34S-40S.

Pires, J. A. A., and R. R. Grummer. 2007. The use of nicotinic acid as antilipolytic to induce sustained low NEFA concentrations in feed restricted Holstein cows. J. Dairy Sci. 90:3725-3732.

Pires, J. A. A., A. H. Souza, and R. R. Grummer. 2007. Induction of hyperlipidemia by intravenous infusion of tallow emulsion causes insulin resistance in Holstein cows. J. Dairy Sci. 90:2735-2744.

Roberts, C. J., I. M. Reid, G. J. Rowlands, and A. Patterson. 1981. A fat mobilisation syndrome in dairy cows in early lactation. Vet. Rec. 108:7-9.

Sakai, T., T. Hayakawa, M. Hamakawa, K. Ogura, and S. Kubo. 1993. Therapeutic effects of simultaneous use of glucose and insulin in ketotic dairy cows. J. Dairy Sci. 76:109-114.

Saloranta, C., A. Franssila-Kallunki, A. Ekstrand, M. R. Taskinen, and L. Groop. 1991. Modulation of hepatic glucose production by non-esterified fatty acids in type 2 (non-insulin-dependent) diabetes mellitus. Diabetologia 34:409-415.

Santomauro, A., G. Boden, M. Silva, D. Rocha, R. Santos, M. Ursich, P. Strassmann, and B. Wajchenberg. 1999. Overnight lowering of free fatty acids with acipimox improves insulin resistance and glucose tolerance in obese diabetic and nondiabetic subjects. Diabetes 48:1836-1841.

Taggart, A. K. P., J. Kero, X. Gan, T.-Q. Cai, K. Cheng, M. Ippolito, N. Ren, R. Kaplan, K. Wu, T.-J. Wu, L. Jin, C. Liaw, R. Chen, J. Richman, D. Connolly, S. Offermanns, S. D. Wright, and M. G. Waters. 2005. (D)- $\beta$-hydroxybutyrate inhibits adipocyte lipolysis via the nicotinic acid receptor PUMA-G. J. Biol. Chem. 280:26649-26652.

Thornton, J. H., and L. H. Schultz. 1980. Effects of administration of nicotinic-acid on glucose, insulin, and glucose-tolerance in ruminants. J. Dairy Sci. 63:262-268.

Vaag, A., P. Skott, P. Damsbo, M. A. Gall, E. A. Richter, and H. BeckNielsen. 1991. Effect of the antilipolytic nicotinic acid analogue acipimox on whole-body and skeletal muscle glucose metabolism in patients with non-insulin-dependent diabetes mellitus. J. Clin. Invest. 88:1282-1290.

Van Epps-Fung, M., J. Williford, A. Wells, and R. W. Hardy. 1997. Fatty acid-induced insulin resistance in adipocytes. Endocrinology 138:4338-4345.

Waterman, R., J. W. Schwalm, and L. H. Schultz. 1972. Nicotinic acid treatment of bovine ketosis. I. Effects on circulatory metabolites and interrelationships. J. Dairy Sci. 55:1447-1453. 